\section{Eics}

How to cite this article: Torres et al. The effects in assistance indicators of changes on a nursing team. ABCS Health Sci. 2021;46:e021222. https://doi.org/10.7322/ abcshs.2020016.1455

Received: Feb 28, 2020

Revised: Oct 05, 2020

Approved: Nov 19, 2020

Corresponding author: Cristina Luiza Ramos da Fonseca - Centro de Pós-Graduação e Pesquisas em Administração - Faculdade de Ciências Econômicas - Universidade

Federal de Minas Gerais - Avenida Presidente Antônio Carlos, 6627 - Sala 4012 - Pampulha - CEP: 31270-901 - Belo Horizonte (MG), Brazil -

E-mail: cristinaluiza@gmail.com

Declaration of interests: nothing to declare

This is an open access article distributed under the terms of the Creative Commons Attribution License

(C2021 The authors

\title{
The effects in assistance indicators of changes on a nursing team
}

\author{
Isabella Moreira Torres ${ }^{1}$, Cristina Luiza Ramos da Fonseca ${ }^{1}$, \\ Allan Claudius Queiroz Barbosa ${ }^{1,2}$ \\ ${ }^{1}$ Centro de Pós-Graduação e Pesquisas em Administração, Faculdade de Ciências Econômicas, \\ Universidade Federal de Minas Gerais (UFMG) - Belo Horizonte (MG), Brazil \\ ${ }^{2}$ Instituto de Estudos Avançados Transdisciplinares, UFMG - Belo Horizonte (MG), Brazil
}

\section{ABSTRACT}

Introduction: This article discusses the path of healthcare associated infections (HAI) indicators in the intensive care unit (ICU) of a public teaching hospital in Belo Horizonte, Minas Gerais, Brazil, after certain change in its nursing staff: pair of nursing caregivers. The model of a pair of caregivers consists in assigning one nurse and one nursing technician for every three patients. The indicators analyzed were infection related to central venous catheters (CVCs), the risk of HAI, turnover, and absenteeism. Objective: The objective of this paper is to understand the impact of the restructuring of the nursing staff in Human Resources and on the rate of infection in the ICU. Methods: As for methods, it is a qualitative and descriptive research carried out as a case study. Results: The results have shown that the risk of HAIs significantly increased after the change in staffing, but the density of vascular access infection associated with CVCs was drastically reduced. The results of turnover of nursing technics decreased and the turnover of nurses increased while the absenteeism of the nursing team decreased after the change. The interviews revealed that there was a gain at the care due to the change. Conclusion: As a conclusion, the results of the study have shown that the proposed nursing model caused a care gain, once the interviews exposed that and indicator directly related to nursing team care (infection associated with CVCs) decreased.

Keywords: primary nursing; Intensive Care Units; quality assurance, health care; health care; workforce; personnel management; hospital administrators.

\section{INTRODUCTION}

This research examines the restructuring of the nursing staff in an intensive care unit (ICU) in a hospital in Brazil, based on the indicators of human resources (HR) and infection related to healthcare and the opinion of interviewed professionals. Given the high cost and complexity of hospitals, the proposition of innovative management models that embrace new management structures and policies has been instrumental in generating quality health services that improve outcomes for the patients and the healthcare system ${ }^{1}$.

Many strategies have been implemented aiming at the optimization of hospital services, and some focus, mainly, on critically ill patients ${ }^{2}$ that can be found at ICUs. It is estimated that, between 18 to $54 \%$ of patients admitted to ICU will have, at least, one healthcare associated infections (HAIs) episode ${ }^{3}$. HAIs represent a big problem 
for health systems due to their effect on morbidity, mortality, length of hospital stays, and higher costs ${ }^{4}$. HAIs are infections acquired during patient care and are associated with quality of patient care ${ }^{4}$. In ICUs, patients are usually more susceptible to HAI by being exposed to poor clinical conditions, having low immunologic function, and requiring many invasive procedures to ensure appropriate assistance ${ }^{5}$. Overall, ICU-acquired HAI represent approximately $20 \%$ of all nosocomial infections diagnosed among hospitalized patients ${ }^{6}$.

One important type of HAI is the bloodstream infections related to central venous catheters (CVCs). The bloodstream infections related to CVCs have a characteristic feature that can be prevented through the action of the caregiver or the institution ${ }^{7}$. The literature indicates that CVC bloodstream infections can be prevented when catheters are inserted, used, and handled correctly, according to evidence-based practices ${ }^{8}$. Hand hygiene is crucial, as it is the use of maximum barrier precautions for catheter insertion (use of a cap, mask, sterile apron and gloves, and large sterile fields covering every area to be punctured), prepare the skin with $0.5 \%$ chlorhexidine alcoholic solution or povidoneiodine, select the CVC insertion site (use of the subclavian vein as the preferred site for non-tunneled (VC) ${ }^{9}$. Nursing personnel play a central role in the care of CVCs once the dressing and care of which are private action of the nurse $\mathrm{e}^{10,11}$.

Some studies show excessive workload as one of the main risk factors for the development of HAI in ICU patients ${ }^{12-14}$. Another study also indicates that working environments with a better relationship between nursing staff by number of patients can result in the decrease in HAI rates, as well as mortality rates ${ }^{15}$. Also, the greater the number of degreed nursing staff, the greater the impact on the survival of patients ${ }^{16}$.

Others studies ${ }^{17-19}$ have evaluated the impact of the design of a workload model and qualification of nurses in patient care outcomes, relating to the performance of HR and health outcomes. Data on the size and profile of the nursing staff suggests that each additional patient per nurse is associated with a $23 \%$ increase in the chances for burnout and a $15 \%$ increase in the chances for job dissatisfaction, which could lead to an increase of turnover, absenteeism, and lower care quality.

Consequently, once the qualifications and professional activities involved influence the patient's assistance, human resource management (HRM) is the central element in the management of healthcare services ${ }^{20}$. HRM are especially important considering that excessive workload, shortage of skilled labor, dropout, and migration of professionals to developed countries are problems in Brazil that make it difficult for nurses to fully perform their duties ${ }^{21}$. Therefore, this research seeks to answer the question: "What is the impact of the restructuring of the nursing staff in the area of $\mathrm{HR}$ and on the rate of infection in the ICU?".

\section{METHODS}

A qualitative and descriptive research was carried out since the aim was to understand a complex phenomenon in its entirety. A case study was chosen to allow enough control and a detailed analysis of the variables. Besides that, this descriptive research was conducted in an ICU in a Brazilian public hospital that experiences difficulties inherent to the public health system. The hospital is managed by a university through a foundation of private law. Its guideline is the construction of patientcentered care, teaching, and management model focused on comprehensive care.

The adult ICU was chosen because of its characteristics: patient severity profile, high mortality rates, and its role as a fundamental support for the care of critically ill patients. This ICU had 30 beds and was coordinated by an intensive care physician and an intensive care nurse. This is more challenging at an ICU where nursing practice is a crucial axis of care management, which is a complex and continuous process that cannot be postponed or interrupted in many situations due to the criticality of patient demand.

It should also be noted that the change of the nursing team performed in the ICU was an innovative and pioneering proposal in the hospital. Thus, having an in-depth understanding of this process of change and its consequences for the quality of care and HR may identify variables that can contribute to the improvement of care and HR indicators, thereby enabling the review of the HRM policies and minimizing its gaps.

The main objective of this study was to examine the impact of a chance at nursing team occurred in April, 2012, when a pair of nursing caregivers were implemented. At that time, the hospital's HRM with the hospital board decided to define a nurse and a nursing technician to every three patients (pair of nursing caregivers). That decision meant an increase of nurses at the ICU, and it was expected an improve of healthcare quality.

Data were collected considering three categories: change in the nursing team, HRS results and quality indicators for healthcare. The category "change in the nursing teams" aims to show how the change of the pair of caregivers and the reasons for it. The category "HRS results" displays the impacts of the change at the selected HRM indicators: turnover and absenteeism; and the category "quality indicators for healthcare" presents the path of the HAI risk indicator and CVC related infections indicator.

The turnover indicator was chosen because turnover can cause dissatisfaction in the workplace, disagreements within the staff, and difficulties in service to the user due to service outages ${ }^{22}$ and loss of experienced professionals ${ }^{20}$. Besides, a big turnover rate decreases the quality of care and increases the operating cost of health services ${ }^{23}$. Nursing absenteeism can negatively affect the quality of care provided to patients ${ }^{24}$ "by causing the service to be disorganized, generating dissatisfaction and overload 
among the present professionals, especially when the absence is not communicated in a timely manner so that the shift can be covered" 25 . Because of the impacts of these factors, they were selected as HR indicators to evaluate the implementation of the pair of nursing caregivers.

For the healthcare quality indicators, HAI risk indicator was selected since most of HAI (approximately of 70\%) can be preventable by the correct adoption of prevention practices by the healthcare professionals ${ }^{26}$. Due to the severity of infections that increase patient morbidity and mortality and cost evolved, HAIs are considered a public health problem ${ }^{4}$. As for the CVC related infections indicator, the care and maintenance of the CVC is a responsibility of the nurse ${ }^{11}$, that means that it is an ideal indicator to effectively measure the impact of the grow of nurse at ICU, with almost no interference of other variables.

The data were collected through semi-structured interviews, document analysis, indicators database, and institutional reports. For the semi-structured interviews, nurses and other professionals who had been admitted to the institution before March 2012 were selected to report their experiences and perceptions of the change in the nursing staff. In the case of nurses, it was necessary to interview professionals hired in April 2012 (during the change implementation period) due to the absence of active professionals hired before that date. Twenty-six people were interviewed, as shown in Table 1.

Information on HR and HAI indicators (HAI risk and CVC related infections) were collected through management reports and the institution's database, aiming at surveying the historical series of monthly indicators, from January 2010 to July 2018.

The data were analyzed considering the categories, using descriptive statistics for the HR and HAIs indicators and content analysis for the interviews. The results were synthetized at the results section.

Table 1: Subjects interviewed

\begin{tabular}{|l|c|c|}
\hline Category & Office & $\begin{array}{c}\text { No. of } \\
\text { respondents }\end{array}$ \\
\hline $\begin{array}{l}\text { Board/ } \\
\text { Advisory }\end{array}$ & $\begin{array}{c}\text { Managing Director * (at time of } \\
\text { change) }\end{array}$ & 1 \\
\hline & Assistant Technical Director & 1 \\
\hline & BR Advisor (at time of change) & 1 \\
\hline Leadership & Nursing Manager & 1 \\
\hline & ICU Nursing Coordinator (at time & 1 \\
\hline of change) & 2 \\
\hline ICU & ICU Medical Coordinator & 1 \\
\hline professionals & CCIH Coordinator & 1 \\
\hline Total & Physical Therapy Coordinator & 1 \\
\hline & Nursing Technician & 5 \\
\hline & Nurse & 4 \\
\hline
\end{tabular}

\section{RESULTS}

By analyzing the internal and external factors that influenced the change in the nursing team model, it was identified several critical factors inherent to the health context and to hospital institutions: compliance with legislation; the absenteeism, turnover and poor commitment of HR; the low availability of experienced nursing technicians in 2011 and 2012 and the gradual increase in degreed nurses; the tendency of the hospital, as a teaching institution, to accept innovative propositions; and the profile of nursing coordination.

Regarding the restructuring of the nursing staff, the research could verify that the HR Department participated actively in seeking alignment and rapprochement between the assistance and $\mathrm{HR}$ demands and the institutional interests in implementing improvements without any significant financial apportionment. The HR Department likewise assisted the actors involved in this negotiation to construct a viable alternative that represented the best cost-benefit at the time. The data also indicated that HRM played a strategic role by establishing a direct influential relationship with decision makers and by acting based on institutional guidelines.

The data showed that the hospital's HR Department had gaps in HR policies (performance, remuneration, recruitment, and selection), since some of them were based on legal guidelines that did not consider the actual conditions of the institution's staff. There was no evidence that the HR Department used the welfare indicators to define and evaluate the HR practices.

Despite this scenario, HRM could play a key role in the control of absenteeism and turnover. Before the research, actions intended to improve the rates of absenteeism, turnover, or the quality of care, particularly for the ICU nurse's category, had not been identified.

The analysis of turnover indicator suggested that the restructuring of the nursing staff in 2012 had reflected positively in the reduction of nursing technician turnover, which fell from an average of $5.3 \%$ to $3.5 \%$. This reduction, and the increase of length of stay of the nursing technicians in the institution, may be linked to some elements pointed out by them in the interviews. For these professionals, the presence of a nurse in bedside care brought greater security for the technician when providing care to the patient; some felt valued, since the nurse began to perform the same activities that the technician performs.

Although the average turnover of nursing teams has remained the same even after the implementation of the pair of caregivers (one nurse and one technician for every three beds), there was an increase in shutdown requests by the nurse employees (from 1.4 to 2.0 shutdowns/month) plus a reduction in the nurses' average length of stay (from 1.7 to 1.5 years), demonstrating difficulty in retention. In the interviews, the nurses pointed out that the proposed model generated overload for the category. Another aspect identified as influencing turnover was the profile of one of the previous nursing coordinators. 
The evaluation of absenteeism showed one downward trend, due, primarily, to the reduction of absenteeism of nurses (down from $6.9 \%$ to $4.6 \%$ ). However, the indicator showed a rising trend for both technicians and nurses. Regarding the nurses, this upward trend may be related to the work overload identified by some professionals and the perception of their devaluation as a nurse.

Concerning the welfare conditions, according to the interviewed professionals, the pair of caregivers brought significant improvements to patient care. The most evident advance was in the quality in the execution of the procedures and care activities by nursing team. The interviewees point out that these were a result of the growth of average time of educational level and the critical supervision of the nurse. Other improvements identified by the interviewed professionals were that the management of patient's care and a more humanized care.

The professionals generally assessed that there was a significant reduction in the number of infections after the change. The nursing staff attributed the improvement to the skilled work of the professionals, especially in applying dressings, in compliance with the protocols and infection control routines, in contact with the patient, in the procedures, and in bed care.

In addition to these elements, the medical team emphasized catheter and airway care. According to the nursing coordinator, there was an improvement in the awareness and accountability of nurses in relation to the care provided to the patients and the infection control standards. Furthermore, there was an increase in the number of nurses trained and an implementation of new care routines. Another element added by the board was related to the greater ability of the nurse, as a higher-level degree professional, to charge the nursing technician and other professionals to comply with the routines and rules established by the unit.

Although there was a perception that the nursing model (pair of caregivers) had a positive influence on infection control, the average risk of infection related to healthcare in the ICU (HAI risk indicator) increased considerably (average rate from $28.2 \%$ to $35.7 \%$ with an increase trend) after the change at nursing team (employment of a pair of caregivers). Regarding the rate of vascular access infection associated with the CVC, the improvement was evident (reduction from 3.5 to $1.0 \%$ ). After insertion of the pair of caregivers, the rate dropped to an average of one CVCassociated vascular access infection per 1000 catheters-day.

\section{DISCUSSION}

The data indicated that HRM played a strategic role by establishing a direct influential relationship with decision makers and by acting based on institutional guidelines, trying to improve the hospital performance ${ }^{27}$, once it is heavily influenced by effective HRM practices ${ }^{28}$.

Regarding the effectiveness of HRM, some authors ${ }^{18,19}$ draw attention to the need to also relate the HR function to welfare outcomes, such as mortality of patients. From this perspective, the hospital's HR Department has a long way to go. As the data has shown, HR Department needed to link its practices of HR with welfare indicators to check if the chosen path is correct. Some authors emphasize that other indicators, in addition to turnover and absenteeism, must be used if the HR Department intends to be a strategical human resource management, as the literature points out ${ }^{20}$.

Considering the HR indicators, the turnover results support with the literature ${ }^{18,29}$. The lower retention of nurses in hospitals can be related to overhead and high levels of burnout and dissatisfaction, associated to organizational practices. The absenteeism indicator results corroborate with studies that point out that nursing workers' absences are related to illnesses caused by physical and mental tiredness, to daily working hours, to the perception of work over$\operatorname{load}^{30}$, to commitment to the job, and to the nature of the work ${ }^{31}$. These two indicators are important not only to check the effect of the change in the nursing team, but also to the patient's care quality and mortality, as shown in a previous study ${ }^{32}$. Harrisson et al. ${ }^{32}$ highlight that low staffing (nurses or nursing technician) is associated with an increase of mortality from $2.3 \%$ to $9.1 \%$.

The data from the interviews corroborate with studies that suggest that nurses are more likely to exhibit crucial behaviors focused on quality of care and patient safety, such as problem solving, performing complex functions, and effective communication $^{15-17,19}$. Also mentioned as an important role was improving the access and monitoring of patients and their families ${ }^{23}$.

The interviews also validate the finds that suggest that nurses are more likely to behave appropriately in relation to patient safety and have a better performance, since they are qualified to accomplish complex functions ${ }^{18}$. Furthermore, in such circumstances, nurses can communicate more effectively ${ }^{33}$. From this perspective, the improvement in the professional qualification of the ICU workforce can be assessed as a positive aspect of the restructuring of the nursing team.

Regarding the healthcare quality indicator, the HAI risk indicators showed an increase after the establishment of pair of nursing caregivers. That was not expected, considering the literature. A study ${ }^{19}$ demonstrates scientifically that increasing the number of nurses is associated with better outcomes for surgical patients: the chances of mortality of patients increased by $7 \%$ for each additional patient in the nurse workload in hospital, while an increase in the number of patients per nurse from four to six and from four to eight would be accompanied by an increase of $14 \%$ and $31 \%$ in mortality, respectively.

Another study ${ }^{34}$ proves that a $10 \%$ increase in share of baccalaureate degree nurses means an increase of $24 \%$ chances of surviving among patients who experienced in-hospital cardiac arrest. Therefore, considering that the change in the nursing staff conducted to an increase of baccalaureate degree nurses and a decrease of workload for nursing technician, it was expected an improve of care quality and a decrease at HAI risk. 
The result may reflect other variables as shown in additional studies $^{17-19}$. These studies show that, in addition to the design and qualification of personnel, work model organization is essential to ensure patient safety and healthcare quality. Care improvement in an ICU is related to a combination of factors, which include team size, staff qualification and systematization, and monitoring of the work process ${ }^{21}$.

Given the multiplicity of factors involved in the risk of HAI within the hospitals and ICU, further studies are necessary in order to identify the causes of this rise and to establish a relationship between risk of infection and nursing practice ${ }^{33,35}$. Thus, although the interviews showed the improvement caused by the increase in the number of professionals with a higher education, it is necessary to continue to monitor and qualify the work processes.

Whereas infection associated with CVCs indicators, it showed a decrease stressing a possible improvement of care quality from the nursing team, once the care of a CVC is a privative action of the nurse ${ }^{10}$.

\section{Conclusion}

The purpose of this paper was to analyze the consequences of the implementation of a pair of caregivers, bearing in mind the HR and healthcare selected indicators and the opinion of the interviewed professionals. The study accomplished that and, overall, it showed that the proposed nursing model had as its main motivators the difficulties experienced with the nursing workforce, especially the low qualification, absenteeism, and retention difficulties of technical level professionals and the need to improve the quality of nursing care provided to patients, including more control over the infections related to healthcare.

Regarding the assessment of quality of care, the respondents pointed out that the proposed model brought a gain in care for patients and allowed a reduction in infection rates. Although the HAI risk indicator increased after the change, there was a reduction in the density of vascular access infection associated with CVC, which is a process in which nurses have direct, privately and continuous interaction, evidencing the improvement of the quality of care.

As for nursing technicians, the model appears to have had a positive influence. After the change, there was a reduction in the turnover indicator and an increase in the retention of these professionals. It is believed that those were related with the change of the model due to the professionals' perception that the proposed format brought greater security and a valorization, in addition to the perception of a rapprochement with the nurse, since the two professionals share most of the activities. Regarding absenteeism, the average of the indicator remained stable, and no consistent elements were identified in the professionals' speech, hindering any inference regarding the influence of the model on absences at work.

As for the nurses, the implementation of the proposed model appears to have had negatively influence once it can be noted a trend of increase in absenteeism and turnover indicators. Although the proposed model brought care gains, it is necessary to verify nurses' perception of overload and "devaluation". Thus, it appears that the implementation of some actions, such as those listed below, can help strengthen the nursing model and maintain the positive results: a) understand the organization of the work process of the nurse, identifying whether there are issues related to work overload; b) clarify the role played by nurses in ICU, empowering the nurses in the care manager function, and promoting the recognition of this function by the other categories; c) implement regular meetings of a board with the main indicators; d) promote alignment and feedback to the nursing team, highlighting the evolution of indicators and the gains from the model; e) implement HR policies aiming attracting and retaining nurses with appropriate profiles; f) develop professionals who act according to the care model, and developing the dexterity of nurses in bedside care; g) improve the workers' careers so that they can feel motivated to invest in their formation and work in the institution.

Despite the relevance of $\mathrm{HR}$, investment in HR policies is still a challenge in the health sector, either by budget constraints and/or a lack of knowledge of the returns that can be obtained from these investments. The HR department still has difficulty to relate consistent databases and measurements with HR practices in order to identify the possible contribution each one can make to the outcome of patients' welfare. The demand for improvements in the quality and results of healthcare need to be linked to institutional policies that make the workers feel appreciated.

\section{REFERENCES}

1. Azevedo CS, Sá MC, Cunha M, Matta GC, Miranda L, Grabois V. Racionalização e construção de sentido na gestão do cuidado: uma experiência de mudança em um hospital do SUS. Cienc Saude Coletiva. 2017;22(6):1991-2002.

https://doi.org/10.1590/1413-81232017226.13312016

2. Townsend $\mathrm{K}$, Wilkinson A. Managing under pressure: HRM in hospitals. Hum Resour Manag J. 2010;20(4):332-8. https://doi.org/10.1111/j.1748-8583.2010.00145.x

3. Pereira FGF, Chagas ANS, Freitas MMC, Barros LM, Caetano JA. Caracterização das infecções relacionadas à assistência à saúde em uma Unidade de Terapia Intensiva. Vigil Sanit Debate. 2016;4(1):70-7.

https://doi.org/10.3395/2317-269x.00614

4. Haque M, Sartelli M, McKimm J, Abu Bakar MA. Health care-associated infections - an overview. Infect Drug Resist. 2018;11:2321-33. https://doi.org/10.2147/IDR.S177247

5. BusI KM. Healthcare-associated infections in the neurocritical care unit. Curr Neurol Neurosci Rep. 2019;19(10):76. https://doi.org/10.1007/s11910-019-0987-y 
6. World Health Organization (WHO). Report of the burden of endemic health care-associated infection worldwide: clean care is safer care. Geneva: WHO, 2011.

7. Sousa FC, Pereira JC, Rezende DA, Laura C. Avaliação dos cuidados de enfermagem com o cateter venoso central em uma unidade de terapia intensiva adulto e pediátrica. Rev Adm Saude. 2018;18(70). http://dx.doi.org/10.23973/ras.70.92

8. Perin DC, Erdmann AL, Higashi GDC, Sasso GTMD. Evidências de cuidado para prevenção de infecção de corrente sanguínea relacionada a cateter venoso central: revisão sistemática sem metanálise. Rev Latino-Am Enfermagem. 2016;24:e2787. https://doi.org/10.1590/1518-8345.1233.2787

9. Brazil. Agência Nacional de Vigilância Sanitária (ANVISA). Programa nacional de prevenção e controle de infecções relacionadas à assistência à saúde (2016-2020). Brasília: Anvisa, 2016.

10. Ferreira CP, Querido DL, Christoffel MM, Almeida VS, Andrade M, Leite HC. A utilização de cateteres venosos centrais de inserção periférica na Unidade Intensiva Neonatal. Rev Eletr Enferm. 2020;22(56923):1-8. https://doi.org/10.5216/ree.v22.56923

11. Conselho Regional de Enfermagem de São Paulo (CorenSP). Câmara técnica: Orientação Fundamentada nº 077/2014. Available from: https://portal.coren-sp.gov.br/sites/default/files/ Orienta\%C3\%A7\%C3\%A30\%20Fundamentada\%20-\%20077.pdf.

12. Daud-Galloti RM, Costa SF, Guimarães T, Padilha KG, Inoue EN, Vasconcelos TN, et al. Nursing workload as a risk factor for healthcare associated infections in ICU: a prospective study. PLoS One. 2012;7(12):e52342.

https://doi.org/10.1371/journal.pone.0052342

13. White EM, Aiken LH, McHugh MD. Registered Nurse Burnout, Job Dissatisfaction, and Missed Care in Nursing Homes. J Am Geriatr Soc. 2019;67(10):2065-71. https://doi.org/10.1111/jgs. 16051

14. Ball JE, Bruyneel L, Aiken LH, Sermeus W, Sloane DM, Rafferty AM, Lindqvist R, Tishelman C, Griffiths P; RN4Cast Consortium. Post-operative mortality, missed care and nurse staffing in nine countries: A cross-sectional study. Int J Nurs Stud. 2018;78:10-15. https://doi.org/10.1016/j.ijnurstu.2017.08.004

15. Aiken LH. Evidence-based Nurse Staffing: ICN's New Position Statement. Int Nurs Rev. 2018;65:469-71. https://doi.org/10.1111/inr.12499

16. Aiken LH, Sloane D, Griffiths P, Rafferty AM, Bruyneel L, McHugh $M$, et al. Nursing skill mix in European hospitals: cross-sectional study of the association with mortality, patient ratings, and quality of care. BMJ Qual Saf. 2017;26(7):559-68. https://doi.org/10.1136/bmjqs-2016-005567

17. International Council of Nurses (ICN). Evidence-based safe nurse staffing: position statement. Geneva: ICN, 2018. Available from: https://www.icn.ch/sites/default/files/inline-files/ICN\%20PS\%20 Evidence\%20based \%20safe\%20nurse\%20staffing_0.pdf

18. Aiken LH, Clarke SP, Sloane DM, Sochalski J, Silber JH. Hospital nursing staff and patient mortality, nurse burnout and job dissatisfaction. JAMA. 2002;288(16):1987-93.

https://doi.org/10.1001/jama.288.16.1987

19. Aiken LH, Clarke SP, Cheung RB, Sloane DM, Silber JH. Educational levels of hospital nurses and surgical patient mortality. JAMA. 2003;290(12):1617-23. https://doi.org/10.1001/jama.290.12.1617

20. Rodrigues JM, Torres HOG. Eficiência/desempenho hospitalar e resultados da gestão de recursos humanos - uma aproximação possível?. Rev Eletr Gestao Soc. 2015;9(24):1128-42. https://doi.org/10.21171/ges.v9i24.2077
21. Machado MH, Koster I, Aguiar Filho W, Wermelinger MCMW, Freire NP, Pereira EJ. Labor market and regulatory processes - Nursing in Brazil. Cienc Saude Coletiva. 2020;25(1):101-12. http://dx.doi.org/10.1590/1413-81232020251.27552019

22. Scalco SV, Lacerda JT, Calvo MCM. Modelo para avaliação da gestão de recursos humanos em saúde. Cad Saude Publica. 2010;26(3):603-14.

http://dx.doi.org/10.1590/S0102-311X2010000300017

23. Antwi YA, Bowblis JR. The impact of nurse turnover on quality of care and mortality in nursing homes: evidence from the great recession. Am J Health Economics. 2018;4(2):131-63. https://doi.org/10.1162/ajhe_a_00096

24. Ball JE, Bruyneel L, Aiken LH, Sermeus W, Sloane DM, Rafferty AM, Lindqvist R, Tishelman C, Griffiths P; RN4Cast Consortium. Post-operative mortality, missed care and nurse staffing in nine countries: A cross-sectional study. Int J Nurs Stud. 2018;78:10-15. https://doi.org/10.1016/j.ijnurstu.2017.08.004

25. Carneiro TM, Fagundes NC. Absenteísmo entre trabalhadoras de enfermagem em unidade de terapia intensiva de hospital universitário. Rev Enferm UERJ. 2012;20(1):84-9.

26. Ferreira LL, Azevedo LMN, Salvador PTCO, Morais SHM, Paiva RM, Santos VEP. Nursing care in healthcare-associated infections: a scoping review. Rev Bras Enferm. 2019;72(2):476-83. http://dx.doi.org/10.1590/0034-7167-2018-0418

27. Zhao $H$. Research on the Impact of Strategic Human resource management on enterprise performance. Adv Soc Sci Educ Hum Res. 2017;96:113-17.

28. Lee KJ. Strategic human resource management for universityindustry collaborations in Korea: financial incentives for academic faculty and employment security of industry liaison offices. Technol Anal Strat Manag. 2018;30(4):461-72. https://doi.org/10.1080/09537325.2017.1337885

29. Back CY, Hyun DS, Jeung DY, Chang SJ. Mediating Effects of Burnout in the Association Between Emotional Labor and Turnover Intention in Korean Clinical Nurses. Saf Health Work. 2020;11(1):88-96. https://doi.org/10.1016/j.shaw.2020.01.002

30. Costa FM, Vieira MA, Sena RR. Absenteísmo relacionado às doenças entre membros da equipe de enfermagem de um hospital escola. Rev Bras Enferm. 2009;62(1):38-44. http://dx.doi.org/10.1590/S0034-71672009000100006

31. Ticharwa M, Cope V, Murray M. Nurse absenteeism: An analysis of trends and perceptions of nurse unit managers. J Nursing Manag. 2019;27(1):109-16.

https://doi.org/10.1111/jonm.12654

32. Harrison JM, Aiken LH, Sloane DM, Carthon JMB, Merchant RM, Berg RA, et al. In Hospitals With More Nurses Who Have Baccalaureate Degrees, Better Outcomes For Patients After Cardiac Arrest. Health Aff (Millwood). 2019;38(7):1087-94. https://doi.org/10.1377/hlthaff.2018.05064

33. Dorfey ES. Representações sociais das infecções relacionadas à assistência à saúde por profissionais de saúde que trabalham em unidades de terapia intensiva. [master's thesis]. [Goiânia]: Pontifícia Universidade Católica de Goiás, 2016.

34. Needleman J, Liu J, Shang J, Larson EL, Stone PW. Association of registered nurse and nursing support staffing with inpatient hospital mortality. BMJ Qual Safety. 2020;29(1):10-18. http://dx.doi.org/10.1136/bmjqs-2018-009219

35. Nogueira JC, Padoveze MC, Lacerda RA. Governmental surveillance system of healthcare-associated infection in Brazil. Rev Esc Enfermagem USP. 2014;48(4):657-62. https://doi.org/10.1590/S0080-623420140000400012 